DOI 10.1515/linpo-2017-0015

\title{
English orientating constructions denoting location: classification and article use
}

\author{
Nataliia Talavira \\ Nikolai Gogol State University of Nizhyn \\ nataliia.talavira@ndu.edu.ua
}

\begin{abstract}
Nataliia Talavira. English orientating constructions denoting location: classification and article use. The Poznan Society for the Advancement of the Arts and Sciences, PL ISSN 0079-4740, pp. 101-120

The paper singles out English orientating constructions which refer to constant coordinates meant to position situational changeable entities, e.g. at eye level, on hand, in part, in detail. The analysis of constructions denoting location reveals their entrenchment in mind in the basic - articleless - form representing situation coordinates on the superordinate categorization level. Orientating constructions have two discursive variants depending upon the article in their structure: definite and indefinite. The definite article refers to the reference points imposed by a particular situation which is signalled by the combination of orientating and extending constructions while the indefinite article points to the establishment of new coordinates.
\end{abstract}

Keywords: orientating construction, image schema, definite noun phrase, indefinite noun phrase, immediate construction, extended construction.

\section{Introduction}

The structure, meaning and functions of orientating constructions traditionally treated as prepositional phrases without articles have been analysed from varying perspectives. As for the structure, two elements draw scholars' attention: the use of prepositions (Contini-Morava \& Tobin 2000) and absence of articles (Berezowski 2009) considered as inexplicable by some linguists (Lyons 1999: 51). As for the meaning, separate semantic groups of the phrases in question have been discussed: those indicating boundaries of typical human activity (Quirk et al. 1985: 280; Taylor 2007: 162), time (Reid 2004: 107) and state (Evans \& Green 2003: 125, 188). As for the function, some of them - in fact, in addition - are treated as discourse markers (Schwenter \& Traugott 2000; Lewis 2006; Aijmer 2007).

New perspectives on the analysis of prepositional articleless phrases are opened by their treatment in language teaching as lexical chunks, i.e. conventionalized form/function composites (Nattinger \& DeCarrico 1992: 1), or in $\mathrm{CxG}$ as constructions viewed as pairings of form, meaning and function (Goldberg 2006: 209). 
Lexical chunks and constructions seem similar in structure but different in function.

Structurally, chunks and constructions are considered to be ready-made linguistic units: the former include short phrases that function like 'individual words, collocations, idioms, institutionalized expressions' (Burridge \& Stebbins 2016: 66), the latter consist of anything from a morphological element or lexical item to a complex and abstract syntactic pattern (Hilpert 2008: 14; Eckhoff 2011: 6). Both lexical chunks and constructions are treated as prefabricated linguistic units which need only minimal modification to be used in communication (Dąbrowska 2010: 203). Lexical chunks are considered to be stored in our memory banks as ready-made units (Burridge \& Stebbins 2016: 66). Constructions are entrenched in long-term memory, i.e. 'cognitively routinized due to frequent use' (Zeschel 2009: 187).

Though both lexical chunks and constructions have a fixed structure they allow some transformations due to the slots available in their form, i.e. participant roles associated with a construction or a verb (Goldberg 1995: 49), determining certain syntactic transformations (Nattinger \& DeCarrico 1992: 1, 8), differing from one use to the next (Goldberg 2006: 39, 90), cf. at risk, at imminent risk, at the risk of delaying the negotiations. As the cited examples suggest, the construction at risk has slots for the attribute imminent and for the definite article and the preposition of joining the extending construction.

The main difference between lexical chunks and constructions concerns their functioning. The chunks, studied at the surface level, are believed to facilitate speech fluency under real-time conditions (Wray 2002) in predictable contexts (Wible 2010: 165). The deeper - grammatical - study concentrates on constructions viewed from two perspectives: paradigmatic, concerning different levels of meaning generalization, and syntagmatic, focusing on their linear expansion. Paradigmatically, constructions are divided into item-based, lexicalized and grammaticalized (Tomasello 2000: 62). Even though 'potentially decomposable' into constituents item-based constructions are stored and used as single units, e.g. You keep out of this (Tomasello 2000: 62). Lexicalized constructions with islands of reliability, i.e. 'relatively stable frames of reference in speech stream' (Diehl et al. 1987: 564), are relatively abstract, e.g. Let's $X$ it, There's a X. Grammaticalized constructions are highly abstract entities based on commonalities in the forms and functions of a whole host of different specific expressions, e.g. negation constructions; motion construction (Tomasello 2000: 62).

Syntagmatically, constructions fall into immediate, modified and extended. Immediate constructions consist of a word with dependent units joined on the left, e.g. in hand, at national level, or on the right, e.g. in danger of ruin. Immediate modified constructions admit additional elements expressed by adjectives, cf. under pressure vs under constant pressure, or pronouns, cf. at risk vs at his risk. Extended constructions combine two or more immediate ones, e.g. For Arab Israelis, who make up 20 percent of the country's population, the legislation strikes at the heart of their identity (Newsweek: 02 June 2017). In the cited example, the immediate modified variant at the heart, derived from the articleless construction at heart, is extended by units the legislation strikes on the left and of their identity on the right.

Drawing on the suggested grammatical approach to prefabricated phases this paper treats the prepositional articleless units like in hand, on view, on top as orientating con- 
structions, i.e. a unity of form and meaning, meant to refer to constant coordinates positioning situational changeable entities. In this vein, fixed coordinates refer to components of a situation such as participants' state (in love), space (on land), time (at night), activity (on trial), its instruments (by plane) and parameters of objects (in size), while changeable entities located relative to these coordinates may be people (child at risk), physical objects (handcuffs in particular), emotions (joyful at heart), actions (eat in space) or its result (no solution in sight), abstract notions placed in space metaphorically (the crisis at hand).

The aim of the study is to explain the use of definite and indefinite articles within orientating constructions (OCs). Implementing the method of continuous sampling of orientating articleless constructions and their discursive variants from 730 online articles of Newsweek and The Spectator magazines we determine the use of definite/indefinite article within basically articleless OCs taking into account semantic groups of these units.

The structure of the paper is as follows: Section 2 defines the constructions under study; Section 3 suggests a corpus-based study of orientating constructions denoting location and their discursive - definite and indefinite - variants.

\section{English orientating constructions: unity of form and meaning}

The articleless units under study treated as orientating constructions since they denote fixed coordinates providing for positioning situational changeable entities can be specified with regard to the unity of form and meaning.

Structurally, the entrenched form of the OCs consists of a preposition and an articleless noun, e.g. in space, on hand. Like other constructions, the meaning of the units under study is 'maximally generalized with no redundant representation of specific examples of a given pattern' (Zeschel 2009: 187). OCs have discursive variants with definite or indefinite article within their structure.

The unity of the OC's form and meaning derives from the integrity of image schemas, i.e. recurring dynamic patterns of our perceptual interactions and motor programs that give coherence and structure to our experience (Johnson 1987: xiv). The classification of OCs suggested in this paper rests on four types of image schemas: bodily, perceptual, moto-topological and dynamic (Potapenko 2016: 14).

The integration of form and meaning of somatic constructions derives from bodily schemas FAR - NEAR, UP - DOWN, FRONT - BACK, CENTER - PERIPHERY indicating 'the position of conceptualized objects relative to the human body' (Potapenko 2016: 14), e.g. in front of, at hand.

The interaction of form and meaning of perceptual constructions is based on the succession of schemas MASS - COLLECTION - COUNT - OBJECT capturing the visual 'transformations of the objects which are approached or perceived from distance' (Potapenko 2016: 14), for example, the phrases in abundance, indicating a large amount of objects, or in part, denoting a fragment of a referent.

The form and meaning unity of object-related constructions rests on moto-topological schemas OBJECT - SURFACE / CONTACT - CONTAINER - FULL / EMPTY repre- 
senting a gradual motion into CONTAINER, being in it or getting out, e.g. to school, in love. In the latter example the preposition in represents the state of affection as a container.

The unity of form and meaning of dynamic constructions derives from the schemas which split into kinetic, 'distinguishing the trajectories of moving objects' (Potapenko 2016: 14) in terms of PATH (Johnson 1987: 113), e.g. on course, to college, VERTICALITY (Johnson 1987: xiv), e.g. on top, at ground level, and those for force which include ENABLEMENT / DISABLEMENT, ATTRACTION, BLOCKAGE, RESTRAINT, REMOVAL, DIVERSION, COMPULSION, COUNTERFORCE, (Johnson 1987: 42, 4547), e.g. in conflict, in opposition, representing COUNTERFORCE.

The use of articles with OCs depends on three categorization levels: superordinate, basic and subordinate (Rosch 1978: 30-31). The superordinate level is characterized by abstract categories sharing only a few common attributes (Rosch 1978: 31), being 'conceptually vague and undifferentiated' (Taylor 1995: 50). Thus the nouns, denoting these categories, are articleless since they reflect relations of generalized nature and independent from the parameters of a particular situation. The basic categorization level mainly rests on perceptual attributes and common motor movements (Rosch 1978: 32-33) being signaled by the indefinite article, representing the establishment of relations from a participant's point of view. The subordinate level encompasses objects which are very similar to each other and have both low identifying ability among other members of the category and low generalization (Rosch 1978: 35) which is signaled by the definite article.

(1) The WHO FCTC conference decisions, designed for implementation at national level by signatories, have a direct bearing on the nearly $\$ 800$ billion global tobacco industry [Newsweek: November 01, 2016],

(2) Co-operation between the three left-wing parties in Berlin has raised interest in German politics due to the possibility of their pursuing a coalition at a national level [...] [Newsweek: July 20, 2017],

(3) Advertising and marketing will be strictly regulated at the national level, as with tobacco. Trudeau's bill sets a minimum purchase age of 18 [Newsweek: April 23, 2017].

In the cited examples, the articleless construction at national level (1) locates Indian tobacco industry against the background of the world-wide repercussions denoted by the adjective global. The indefinite noun phrase (NPh) at a national level in (2) indicates a collective view at which German politicians plan to build a coalition. The definite $\mathrm{NPh}$ at the national level in (3) subordinates the advertising regulating to the state level, revealed by the unit bill.

To sum up, it is due to image schemas that constructions with a fixed structure and meaning in their basic - articleless - form indicate constant coordinates positioning situational changeable entities. Our hypothesis is that the use of articles within these con- 
structions is determined by the degree of dependence of the denoted coordinates on the event participants: the indefinite article signals establishing particular coordinates while definite variants of the articleless constructions refer to the situational coordinates providing for a particular state of things. Being most frequent, constructions denoting location indicate an entity's position in space at different distance from the body of an individual.

\section{Corpus-based study: orientating constructions denoting location}

Since unity of form and meaning of the discussed units is based on image schemas underlying human orientation in the environs (Potapenko 2016: 14), OCs denoting location fall into four groups: somatic, referring to space around an individual's body, e.g. in sight, on hand; perceptual, indicating referent conceptualisation from varying distance, e.g. in bulk, in part; dynamic, pointing to reference points providing for motion, e.g. on course, in retreat; and vertical, indicating upright coordinates, e.g. on top, at ground level.

3.1. Somatic constructions name referent arrangement relative to different parts of human body from three perspectives: central, connected with the heart, e.g. at heart; frontal, setting the visual field, e.g. on view; and lateral, locating fixed coordinates on the conceptualizer's left or right sides, e.g. at hand.

The OC at heart manifests central localization in two forms: articleless and definite.

The articleless construction at heart hinges on the CENTER image schema indicating the midmost coordinate due to the conceptual metaphor mapping the organ in the centre of the chest to the innermost part of a person in which his/her deepest feelings are located (MWD). The superordinate status of this immediate construction is underscored by the existential verbs be and remain indicating the location of the most basic characteristic of a person in (4).

(4) (...) he (Obama) cares about domestic policy but has no passion even for a war he insists is a necessity. Middle East expert Fouad Ajami put it this way: "He fights the war with Republican support, but his constituency remains isolationist at heart" [Newsweek: January 06, 2011].

In example (4) the articleless immediate OC at heart reflects the deepest - isolationist - characteristic of a group of voters metonymically denoted by the collective noun constituency.

The definite variants of the analysed articleless construction are represented by two prepositions indicating situational coordinates: at the heart and in the heart. As a result of metaphorical mapping the definite NPh at the heart locates referents in the centre of an entity due to the preposition at (Tyler \& Evans 2003: 178), e.g. at the heart of the town, at the heart of the continent, while the definite NPh in the heart with the preposition in places referents in the centre of a three-dimensional space (Drozdowicz 2001: 35), e.g. in the heart of Paris. 
Both variants possess the definite articles due to the extending constructions joined by the preposition of to denote the background for the indicated centre. However, the definite NPh at the heart indicates the centre of a physical or abstract space. The physical space is represented by the combination of at the heart construction with those naming various territories or places (at the heart of the town, at the heart of the North London destination) as in (5) where the definite $\mathrm{NPh}$ at the heart locates a country in the centre of Europe.

What do you call the country that sits at the heart of Europe, which is its biggest and strongest economy, and which increasingly calls the tune in the European Union? [Newsweek: October 06, 2014].

The abstract space is represented by the extending of-constructions denoting particular political or economic spaces: at the heart of the crisis, at the heart of liberty, at the heart of modernity, at the heart of the strategy. In (6) the definite NPh at the heart places Russia in the center of global politics.

(6) Far from putting Russia at the heart of world politics, Putin is, in fact, increasingly isolating his country [The Spectator: March 22, 2018].

By contrast, the definite NPh in the heart indicates a referent in the centre of a physical space represented by particular squares (in the heart of Times Square), cities (in the heart of London, in the heart of the Dutch capital), provinces (in the heart of Texas), countries (in the heart of India).

(7) As commuters in the heart of Nairobi hustle past one another at the end of a recent workday, young men are buying machetes in a hardware shop before boarding a bus [Newsweek: June 02, 2017].

In (7) the definite NPh in the heart locates commuters in the centre of Kenya's capital, Nairobi, by the of-phrase which connects it with a particular space bringing about the use of the definite article.

OCs indicating frontal orientation encompass two subgroups: inclusive, establishing the boundaries of a visual scene (in sight, in full view) and panoramic, including all the viewed objects (on view).

The frontal inclusive OCs in sight and in full view, setting the limits to the visual field, are always articleless as they denote a three-dimensional backdrop with fixed boundaries for locating different objects. Consequently, the immediate construction in sight denoting a fixed visual field combines with preceding nouns or pronouns indicating people (policemen in sight, everyone in sight) or objects (everything in sight). In (8) the articleless OC in sight indicates a visual field for locating oak trees.

(8) There were few oak trees in sight [The Spectator: May 24, 2017]. 
The OC out of sight with the meaning opposite to the one analyzed above indicates the inaccessibility of the visual field as well as the entities it includes. As a result, in (9) a plastic black binder with its contents turns out to be invisible.

(9) Tucked out of sight on a shelf in the former station-master's office, a plastic black binder contains details and photographs of what became known locally as The New Year's Day Tragedy [Newsweek: November 21, 2014].

An overall-inclusive localization is construed by the modified construction in plain sight with the adjective plain underscoring a free field of vision providing for the perception of entities with negative connotation: illegal (conspiracy hiding in plain sight), dangerous (the biggest threat breeding in plain sight) or unpleasant (an inconvenient truth in plain sight). The articleless construction in plain sight in (10) underscores crimes placing them in an unobstructed visual field and making them visible to everyone, while the adjective greatest emphasises their unique nature.

(10) But some of the greatest crimes have been committed in plain sight [Newsweek: February 14, 2017].

Synonymic constructions in full view and on view with the noun view, indicating an entity's visibility, portray referents from two perspectives determined by the prepositions with the articleless form denoting supersituational categorization. The all-inclusive OC in full view places referents inside the visual field with the adjective full underscoring the perception of all available contents.

(11) [...] the wrought-iron Metal Wine Cage can keep a dozen vintages in full view while safeguarding them under lock and key [Newsweek: December 10, 2009].

In contrast to two frontal inclusive constructions, the panoramic OC on view sets the background for art exhibitions by the preposition on locating one object on the outer surface of the other (Goddard 2002: 283) with artefacts placed on the horizontal or vertical plane accessible to the public. The supersituational OC on view is extended by nouns emphasizing availability of exhibits to viewers: they denote artworks (Susan Morris's "Motion Capture Drawing...," on view in Venice) or places of display (on view in the museum, on view at the art gallery).

(12) An early score of Orfeo is held in Venice's Biblioteca Nazionale Marciana and will be on view in London this fall as part of a loan to the Victoria and Albert Museum's "Opera: Passion, Power and Politics” exhibition [Newsweek: April 21, 2017].

The lateral OCs locating entities relative to hands include three prepositions: at, indicating a point; on, locating an object on the surface; in, construing hands as three-dimensional spaces. Due to metaphoric mappings, these OCs reveal successive stages of 
object's accessibility: its attainability, i.e. easy reach (at hand); its availability, i.e. being in full view (on hand); its possession due to construing a hand as three-dimensional space (in hand).

The meaning of referent's attainability, expressed by the OC at hand, results from a short distance between the hand and an object with the latter being located very near (Collins) at an arm's length, rendered by the image schema NEAR (Johnson 2005: 20) while the linguistic generalization of two hands into a unity results in the absence of the article. The extended constructions signal an object's attainability in space or in time: workshops at hand, the job at hand, the dictionary at hand. The OC at hand in (13) locates a clavichord close enough for the person to play it.

(13) Enter Beckmesser with his lute, except that he doesn't have one, but a clavichord is at hand, which he plays [The Spectator: July 09, 2017].

In (14) the combination of the articleless construction at hand with the noun task reflects a temporal imminence of a military strike.

(14) In any pre-emption scenario now, the U.S. would try to keep the strike limited to the task at hand; at the same time, Washington would signal in any way it could - probably via the North's ally in Beijing - that it did not seek a wider war [Newsweek: April 25, 2017].

The articleless construction on hand implies the generalized availability of an object placed on a palm schematized as a surface indicating the outer part on which entities are easily affordable (money on hand, a GPS unit on hand) which is the case in (15).

(15) Cook's Apple has $\$ 237$ billion in cash on hand, and could single-handedly fund some new way to produce and market great journalism from now until the first news bureau opens on Mars [Newsweek: February 06, 2017].

The OC in hand locates objects inside a palm perceived as a CONTAINER with the independence of size determining an articleless form as in (16).

(16) These things were true before Huffington came down the mountain, artisanally hewn revelatory tablets in hand [Newsweek: January 05, 2017].

The OC in hand is extended by nouns denoting abstract entities especially in the business or medicine sphere (deal in hand, information in hand). In (17) the articleless construction in hand denotes scientists' possession of a genetic signature enabling further treatment of patients.

(17) But a new study has uncovered a particular genetic signature that indicates the one-third of intermediate-risk prostate cancers bound to be problematic. With this 
signature in hand, identifying patients who need rigorous treatment up front - as well as those who do not - is now within reach [Newsweek: January 18, 2017].

To sum up, somatic constructions indicate universal coordinates represented by parts of human body such as the heart, the eyes or hands. The somatic OCs reflecting the fixed background for locating objects are articleless in combination with nouns naming people, objects, concepts, while the definite NPhs denote situational coordinates due to collocation with of-phrases referring to three-dimensional spaces in case of central coordinates.

3.2. OCs denoting perceptual localization indicate coordinates of an object perceived from a varying distance as a result of visual transformation of a single homogeneous mass into a cluster of objects and the reverse procedure brought about by the motion of our gaze back and forth relative to our bodies (Johnson 1987: 26). The constructions of this group are used with no article since they indicate generalized mental operations universal for all language users. The four subgroups of the named OCs, based on perceptual image schemas, include the following: schematic (in total), multiple objects' perception (in abundance), quantitative (on average) and meronymic (in part).

The schematic OCs in general and in total evoke the mental operation of correlating a separate object with their group taken as a whole, when the entity is conceptualized as an indivisible MASS. The difference between the two OCs consists in the level of schematization revealed by the extending units: qualitative (in general) and quantitative (in total).

The OC in general sets the perception of objects as a mass indicated by the extending nouns naming bodily conditions (health in general), collective nouns representing a group of people (public in general, community in general) or indicating various establishments (non-governmental organizations in general), as well as units denoting phenomena (innovation in general, discrimination in general). In (18) the articleless OC in general indicates a typical operation of qualitative schematization of innovation as a universal phenomenon.

(18) [...] he steps outside to observe the construction that is transforming his former restaurant into elBulli 1846, a research lab and exhibition space [...] "It's about innovation in general. Gastronomy is just the platform we're using to explore innovation" (Newsweek: April 22, 2017).

The schematic construction in total evokes the mental operation of quantitative generalization which consists in summing up entitites denoted by numerals (40 people in total, 12 million in total, dropped to one fifth in total) or adjectives in the comparative degree (take home less in total). In (19) the articleless form of the immediate OC in total combines with the extending adjective less generalizing on the amount of women's earnings.

(19) As a result, they may earn more each hour than men but still take home less in total [The Spectator: July 23, 2017]. 
OCs in abundance and in bulk, pointing to the mental operation of perceiving multiple objects, indicate grouping large amounts of entities named by collective or plural nouns. The articleless constructions of this subgroup differ in the way the perceived objects are portrayed. Being extended by nouns the OC in abundance represents clusters of objects as MASS with a conceptualizer unable to differentiate separate entities because of their large quantity. In (20) the articleless construction in abundance triggers a universal operation of generalization representing an ample quantity of energy denoted by the noun stamina.

(20) We all knew from his victories in the Hennessy Gold Cup and the Welsh Grand National that Native River possesses stamina in abundance [The Spectator: February 17,2017$]$.

Being extended by nouns in the plural the OC in bulk points to the mental generalization of uniting a large amount of objects perceived as COLLECTION. In (21) the articleless $\mathrm{OC}$ in bulk indicates the perception of emails as a collection available online.

(21) I'm a party member and also received a similar message. It's very easy to personalise emails sent in bulk (...) [The Spectator: December 27, 2016].

The third type of constructions - the quantitative OC on average - indicates the operation of counting which results in obtaining the mean number of perceived objects. Their amount can be expressed by percentage (on average the price has hovered around 30 percent), even numbers (on average, every 85 days) or fractions (on average two third of the group) generalized by the fusion of two image schemas: COUNT representing calculation in number and VERTICALITY underlying the conceptualisation in terms of increase or decrease (Johnson 1987: xv).

(22) Branded drugs are, on average, 32 times more expensive than generics [Newsweek: February 03, 2017].

In (22) the articleless $\mathrm{OC}$ on average points to the operation of calculating the price of drugs with its increase rendered by the extending construction 32 times.

The unity of form and meaning of meronymic OCs, denoting part of the whole with objects perceived from a close distance and thus correlating with the first element of the PART-WHOLE image schema (Johnson 1987: 126), is named by three constructions: partitive (in part), specifying (in detail) and focal (in particular).

The partitive construction in part points to the universal operation of fragmentation. This OC is extended by the nouns indicating fragmentary referent representation, portraying only some segment or piece of it (substantial parliamentary majority is achieved in part by populist votes; they were being enticed, in part, by suggestions), verbs denoting focalization (revitalising Jewish life, in part by focusing on cultural issues) or causal prepositions due to, thanks to and conjunction because (the economy sputters, in part due to Western sanctions; xenophobia is growing, in part due to fake news). The article- 
less OC in part in (23) points to the universal operation of fragmenting a described situation of supporting choices in public education.

(23) The group's goal is "supporting quality choices in public education for all Michigan students," in part by shaming public education [Newsweek: January 10, 2017].

The $\mathrm{OC}$ in part forms a modified construction in large part indicating an operation of singling out a larger component of a particular entity as in (24).

(24) And up to 17 percent of global methane emissions come from rice cultivation. In large part, that's because the warm, waterlogged soil in rice paddies provides ideal conditions for the growth of a particular kind of bacteria known as methanogens [Newsweek: February 10, 2016].

The specifying OC in detail designates the process of zooming-in on an object. The articleless form draws attention to aspects of recommendation (consider the recommendations in detail), planning (the plan reviewed in detail) or communication, both oral (discuss in detail, speak in detail) and written (document in detail, set out in detail). Example (25) illustrates the use of OC in detail singling out the state of the narrator expressed by the abstract noun discontent.

(25) She writes of the "sandy congestion and wind-blown boredom" she witnessed upon arriving at the camp, describing in detail the discontent that led to the Manzanar Riot [Newsweek: February 15, 2017].

The focal construction - in particular - refers to the result of the zooming-in when a prominent aspect of an entity is evoked. The articleless OC in particular singles out a specific feature of an entity represented by nouns denoting: people (in particular the younger hip-hop artists, low-income families in particular), countries (China in particular), human activities (the casting of the show in particular, laughter and singing in particular), artefacts (in particular the official printed version), etc.

(26) In the weeks since Donald Trump was elected president, the behavior of U.S. financial markets - and of the stock market in particular - has represented the triumph of hope over common sense (Newsweek: January 09, 2017).

In sum, perceptual OCs evoke universal mental operations of schematizing, fragmenting, specifying or focalizing which result in the articleless form of immediate constructions extended by nouns and numerals naming entities the mental representations of which undergo those operations or by verbs indicating focalization of actions.

3.3. Orientating constructions providing for kinetic localization name supersituational fixed coordinates of trajectory and direction. 
The trajectory as a kinetic coordinate is evoked by the OCs on track and on course which indicate varying degrees of entity's vicinity to the target denoting unintended or planned results respectively which is reflected by extending constructions. These OCs acquire localization meaning due to the preposition on which brings forth the idea of surface (Balaga 2004: 24) as an aspect of space in which objects can be placed.

The metaphoric meaning of the OC on track is based on the projection of the source domain indicating a contact with surface underlying the trajectory onto the target domain of 'following a course that is likely to result in success' (Collins; Oxforddictionaries). The immediate OC on track is extended by the verbs denoting sticking to the same direction (remains on track, keep its agenda on track) or return to the previous state (get their finances back on track, get right back on track). In (27) the immediate OC on track extended by the construction get their finances back designates return to the previous position, while the generalised meaning of the OC results in the absence of the article.

(27) Indeed, given the level of trauma that victims are having to deal with, it can't just be about helping women get their finances back on track [The Spectator: January 16, 2018].

The OC on track portrays achieving unplanned results extended by infinitives denoting different targets (on track to top next week's general election, on track to win the Democratic nomination, on track to build just $12 \mathrm{GW}$ by 2030, on track to make a billion dollars). In (28) the extended construction on track to make a billion dollars indicates nearing a lucrative aim of making a billion dollars.

(28) Al Gore is a Pied Piper who the New York Times has estimated is on track to make a billion dollars from global warming [The Spectator: September 22, 2017].

The closeness of the final point is indicated by the OC on course extended by for-constructions referring to achievements (on course for reelection, on course for victory) or high office (on course for Downing Street). These accomplishments are intensified by adjectives evaluating success (on course for a resounding victory, on course for a crushing majority) or ordinal numerals underscoring a prominent result (on course for its first gay prime minister). In (29) the extended construction on course for a comfortable victory reflects Macron's closeness to an anticipated win without detailed specification.

(29) The data leak emerged as polls predicted Macron, a former investment banker and economy minister, was on course for a comfortable victory over far-right leader Marine Le Pen in Sunday's election, with the last surveys showing his lead widening to around 62 percent to 38 [Newsweek: May 06, 2017].

The OC in retreat designates backward motion 'away from the enemy after being defeated in battle' (LDOCE: 1213) when the mental operation of generalizing the act of moving back results in the use of the articleless form of the immediate construction as in (30). 
(30) Why are we helping ISIS when they are in retreat? It's clear to anyone with an $I Q$ of triple digits that we are supporting ISIS to destabilise the area so why wouldn't they lie about Assad and Russia gassing children to start a war? [The Spectator: April 12, 2017$].$

More frequent is the metaphoric use of the discussed OC representing a state of 'withdrawal from what is difficult or dangerous' (MWD). In this case, the preposition in imparts the articleless construction in retreat with the meaning of CONTAINER which underscores being in a certain state rather than motion. The articleless OC in retreat is extended by constructions with nouns, naming groups of people literally (his opponents in headlong retreat, Germans in retreat), or metonymically (government in retreat, Old Europe is in full retreat) to indicate withdrawal from a difficult or disagreeable position. In (31) the articleless OC in retreat designates the state of retirement from a complicated diplomatic situation abroad facing Russia, while two other supersituational constructions - in chaos and at home - underscore the generalized representation of the situation.

(31) That he's [Putin] even in a position to try to pull all that off is remarkable, given where Russia was on January 1, 2000: in chaos at home and in retreat abroad [Newsweek: May 18, 2017].

The articleless OC in retreat extended by from-constructions with names of actions (in retreat from accusations), agreements (in retreat from agreed obligations) or viewpoints (in retreat from its ideal) indicates the starting point of relinquishing a certain activity as in (32) where gods withdraw from interfering into the affairs of men and the link-verb are points to a static perception of the situation.

(32) The gods are in retreat from active intervention in the affairs of men [The Spectator: May 27, 2017].

To recap, the OCs indicating dynamic localization are articleless as they indicate kinetic coordinates serving as a background for representing two types of achievement: unintended or planned. The $\mathrm{OC}$ in retreat refers to the coordinate providing for the metaphoric withdrawal from a hazardous or unpleasant situation.

3.4. Orientating constructions providing for vertical localization derive the unity of their form and meaning from the VERTICALITY image schema which as a variant of PATH emerging 'from our tendency to employ an UP-DOWN orientation in picking out meaningful structures of our experience' (Johnson 1987: xiv). In this case DOWN and TOP coordinates correspond to the starting and final points of a trajectory. OCs singled out from the analysed corpus represent coordinates that reflect levels of PHYSICAL, EDUCATIONAL and POLITICAL VERTICALITY.

The OCs indicate two types of coordinates on the PHYSICAL VERTICALITY schema named by extending constructions: spatial and object-related. 
The OCs designating spatial PHYSICAL VERTICALITY locate objects at two levels: terrestrial, serving as a background for the regular human activity (at ground level), and outer spatial, opposed to the former (in space).

The articleless form of the terrestrial OCs, indicating the level by the preposition at, refers to three parameters of PHYSICAL VERTICALITY constant for any situation surficial (at ground level), visual (at eye level) or aquatic (above sea level). The OCs, referring to surface, locate objects on land as the most fundamental reference point (Tyler \& Evans 2003: 108). In (33) the immediate OC at ground level is extended by the phrasal verb stick around to characterise the spread of pollution.

(33) The pollution then tends to stick around at ground level because it's sheltered by mountains so there isn't much wind [Newsweek: March 02, 2017].

The articleless construction at eye level, referring to the universal visual coordinate, locates perceived objects at the level of an observer's eyes which is illustrated by (34) where the $\mathrm{OC}$ under discussion places the entity denoted by the word combination an oak limb.

(34) A red-winged blackbird appeared suddenly, alighting on an oak limb at eye level less than six feet away [Newsweek: May 15, 2016].

The OC above sea level, indicating the aquatic coordinate, points to an entity's position above the average level of the oceanic surface being extended by numeric constructions specifying vertical parameters (4,000 meters above sea level, 3,500 feet above sea level).

(35) A portion of the Scenic Highway in Pensacola, which runs along a bluff 80 to 100-feet above sea level, collapsed in two places, dropping a car and a truck about 40 feet [Newsweek: April 30, 2014].

The articleless constructions in orbit and in space referring to outer space denote the highest possible points of PHYSICAL VERTICALITY. The universal as well as inaccessible character of the coordinates results in its articleless form. With respect to physical orientation the OCs in orbit and in space locate in outer space different entities such as means of communication (a communications-relay system in orbit), instruments (telescopes in orbit), objects of research (plants in orbit).

(36) Besides, a hit on a 15-ton spy satellite would more than double the amount of space debris currently in orbit [Newsweek: March 13, 2009].

In (36) the articleless construction in orbit names a universal coordinate locating moving space debris.

OCs in orbit and in space are extended by the verbs naming different kinds of activities: specialised (do the repairs in orbit, fly in space) or everyday (eat in space). 
(37) Gordon says his students are emailing daily with NASA engineers about the issue, readying a prototype solution to test in space [Newsweek: April 29, 2017].

Constructions denoting object-related VERTICALITY refer to the lower and upper coordinates structuring various physical entities: pieces of furniture, buildings and their parts, natural elevations on the earth's surface, etc.

The articleless OC at bottom, indicating to the lowest point of the PHYSICAL VERTICALITY, designates the real nature of an entity as in (38).

(38) At bottom the objection to Trump may be less substantive than aesthetic [The Spectator: May 31, 2017].

The definite NPh at the bottom combines with of-phrases to refer to the lowest point of a number of phenomena: a particular upright object (at the bottom of a vast canyon, at the bottom of an ancient Athenian well), an imaginary entity (at the bottom of long waiting lists), social hierarchy (at the bottom of the ladder) or economic process (at the bottom of recession). In (39) the definite $\mathrm{NPh}$ at the bottom extended by the of-phrase of the ocean indicates the lowest point of a water body.

(39) In particular, methanogens buried deep inside of rocks eat hydrogen. So do those living in hydrothermal vents at the bottom of the ocean [Newsweek: April 13, 2017].

The upper part of the object-related PHYSICAL VERTICALITY is designated by the articleless OC on top with the preposition on indicating the uppermost point which prevents any further advance with its absolute nature determining the articleless form of the construction. The OC on top is extended by the verbs naming the motion to the uppermost edge of a physical object (climb on top of the kitchen table, put on top of the bowl) or economic entities (get on top of the deficit). In (40) the extended construction climb on top of the box portrays people ascending to upper surface of a container for further activity, i.e. participation in a show.

(40) Every morning, everyone on set, from actors to background artists, claps their hands, says "box, box, box" and gathers around an empty apple box. [...] People climb on top of the box and share things about themselves or their experience on the show [Newsweek: May 06, 2017].

The impossibility of further motion is underscored by extended constructions with static verbs (keep on top of their workload, stay on top of your balance) as in (41).

(41) You only have to stand on top of the ruined towers of ancient Troy, on the western shores of Turkey [The Spectator: February 16, 2018]. 
Vertical situational orientation is indicated by two definite object-based NPhs with the prepositions to and at. The definite NPh to the top implies motion to the highest - but not final - point in combination with nouns naming the trajectory (way to the top) or the verbs denoting motion (ascend to the top, mount to the top, rise to the top). In (42) the definite variant to the top in conjunction with the noun climb represents motion up the status ladder with no definite end.

(42) His climb back to the top [of his father's company] has been swift and surprising, astute and ruthless [Newsweek: December 19, 2016].

In its turn, the definite NPh at the top locates a referent at the highest possible point of a particular entity indicated by the extending of-construction. In (43) the extended construction at the top of their list designates the highest point on the agenda while the pronoun their reflects a situational status of the denoted uppermost coordinate.

(43) Many in industry were unhappy with the agreement. The "majority of the livestock, mining and energy industries bitterly opposed it and have put it at the top of their list to reverse that," Suckling says [Newsweek: January 12, 2017].

As for educational verticality, OCs refer to its three levels: primary (at elementary level), secondary (at school level) and higher (at college level, at university level), while OCs structuring the political hierarchy indicate two levels: regional (at local level) and state (at national level).

The articleless OCs structuring the educational verticality are extended by the verbs denoting routine activity (teach at university level) or by the nouns naming academic subjects taught in different institutions (courses at college level). In (44) the OC at university level extends the predicative construction teaches all courses to locate academic disciplines on the highest level of education.

(44) Oklahoma School of Science and Mathematics, Oklahoma City: A state-funded residential high school that teaches all courses at university level [Newsweek: May 18, 2008].

Definite variants of the constructions under analysis imply the dependence of the named education levels on particular circumstances indicated by extending constructions: noun groups naming particular roles (a head coach at the university level, learning-disabled students at the college level) or institutions (at the university level in Oxford). In (45) the definite construction at the elementary level indicates the stage selected for separation of learners of different races.

(45) At the same time, Haikala acceded to Gardendale's wishes by allowing for a separation [black and white pupils] that would begin at the elementary level_and take place over three years. She will supposedly monitor the process to make sure Gardendale commits to desegregation [Newsweek: May 02, 2017]. 
The indefinite NPhs refer to education levels established by speaker which is indicated by the verbs naming mental (think, believe) or speech activity (say, tell).

(46) "Some things don't happen at a school level, and someone needs to do those," says Gary Richmond [Newsweek: August 26, 2010].

As for the political verticality, articleless constructions structure the political hierarchy into regional or national levels to locate politicians (president, prime minister) or results of their activity (a law, a plan). In (47) the immediate OC at national level relates plans to improve health insurance to the highest level of political hierarchy in the USA while the predicate would be a plan implies a future representation of the situation.

(47) At national level there would be a plan that small businesses and individuals could join, and a national insurance exchange or "connector" for access to private plans that passed tests of quality and did not rate people by their health status [Newsweek: July 01, 2008].

Definite NPhs point to the situational coordinates of particular political events. In (48) the definite phrase at the state level locates problems with a ban on lead-based ammunition and fishing tackle, affecting particular groups of people at a local level.

(48) At the state level, many were upset - and even off ended - that the Obama administration took top-down action without consulting local authorities across the country, and thus breached a long tradition [Newsweek: May 31, 2017].

Indefinite variants of the OCs structuring the political hierarchy indicate the creation of particular levels by units which intensify the process of constructing a personal hierarchy: verbs with the meaning of planning (plans innovations at a federal level) or individual desires (pursuing a coalition at a national level). In (49) the indefinite construction at a national level refers to the hierarchy level desired by the former British prime minister which is underscored by the verb wants.

(49) Cameron has broadly outlined areas in which he wants to win reform from the EU, such as migration controls, retaining lawmaking powers at a national level, and cutting red-tape for businesses [Newsweek: October 20, 2014].

In sum, the analysed articleless OCs structuring verticalities indicate three types of coordinates constant for any situation: physical, providing for terrestrial and outer space orientation; educational, naming various levels of studying and teaching; political, differentiating the level of state hierarchy. Their definite variants provide for the situational level of orientation while their indefinite phrases construe hierarchy levels from a speaker's point of view. 


\section{Conclusion}

The units under study, traditionally viewed as prepositional phrases without articles, are treated in the paper as orientating constructions since they denote fixed coordinates providing for positioning situational changeable entities. The supersituational status of constructions contributes to their articleless form to reflect universal points that help an individual to determine his/her position or an object's location in the surrounds. As coordinates are independent from the communicative situation, the articleless constructions, designating them, have a generalized meaning underscored by extending constructions which include nouns indicating people and their groups literally or metonymically, objects, entities with negative connotation, artworks or places for their display, existential verbs or those, denoting focalization of actions or various targets.

Definite variants denote coordinates locating a particular event on the situational level by extending constructions represented by of-phrases naming various places or entities. Indefinite variants establish new reference points or interpret them in collocation with verbs designating mental or communicative activity.

Drawing on the analysis of the database of the online articles of Newsweek and The Spectator magazines we claim that due to the unity of form and meaning the locating OCs refer to four spatial coordinates - somatic, perceptual, dynamic and vertical. Perceptual OCs, indicating coordinates of object perception from a varying distance, and dynamic constructions, naming coordinates represented by trajectory and a state of withdrawal, are only articleless due to their entrenchment in speakers' mind as a result of repeated use for denoting mental operations. Somatic OCs, indicating coordinates represented by parts of human body such as the heart, the eyes or hands, have definite variants specified by extending of-phrases to represent the background for situational coordinates. Articleless constructions, designating coordinates for vertical localization, have two discursive definite and indefinite variants as it is possible to specify the particular event by the definite article or build a new hierarchy from the perspective of the event participants by the indefinite construction.

Finally, let us signal the issue that deserves exploration, namely orientating constructions indicating such coordinates as temporal (at night, to date) and force (under attack, in opposition).

\section{Sources}

http://www.newsweek.com.

https://www.spectator.co.uk.

\section{References}

Aijmer, Karin. 2008. The actuality adverbs 'in fact', 'actually', 'really' and 'indeed' - establishing similarities and differences. Proceedings of the BAAL Conference 2007, 111-120. London: Scitsiugnil Press. 
Balaga, Monika. 2004. From the actual to the virtual. On the semantics of the preposition 'on'. In Kardela, Henryk \& Sullivan, William J. \& Głaz, Adam (eds.), Perspectives on Language, 23-32. Lublin: UMCS.

Berezowski, Leszek. 2009. The myth of the zero article. London: Continuum International Publishing Group.

Burridge, Kate \& Stebbins, Tonya N. 2016. For the love of language: An introduction to linguistics. Cambridge: Cambridge University Press.

Clausner, Timothy C. \& Croft, William. 1999. Domains and image schemas. Cognitive Linguistics 10(1). 1-31.

Collins: Collins Dictionary; https://www.collinsdictionary.com (Accessed 2018-04-05).

Contini-Morava, Ellen \& Tobin, Yishai. 2000. Introduction. In Contini-Morava, Ellen \& Tobin, Yishai (eds.), Between Grammar and Lexicon, xiii-xxix. Amsterdam (Phil.): John Benjamins Publishing Company.

Dąbrowska, Ewa. 2010. Language, mind and brain. Edinburgh: Edinburgh University Press.

Diehl, Randy L. \& Kluender, Keith R. \& Foss, Donald J. \& Parker, Ellen M. \& Gernsbacher, Morton A. 1987. Vowels as islands of reliability. Journal of Memory and Language 26(5). 564-573.

Drozdowicz, Ariadna. 2001. The image-schematic profile of the English preposition in. Acta Universitatis Nicolai Copernici (English studies X. Humanities and Social Sciences (345)). 17-37.

Eckhoff, Hanne M. 2011. Old Russian possessive constructions: A construction grammar approach. Boston: Mouton de Gruyter.

Evans, Vyvyan \& Green, Melanie. 2006. Cognitive Linguistics: An Introduction. Edinburgh: Edinburgh University Press.

Goddard, Cliff. 2002. On and on. Cognitive Linguistics 13(3). 277-294.

Goldberg, Adele E. 1995. Constructions: A construction grammar approach to argument structure. Chicago: Chicago University Press.

Goldberg, Adele E. 2006. Construction at work: The nature of generalizations in language. Oxford: Oxford University Press.

Hilpert, Martin. 2008. Germanic future constructions: A usage-based approach to language change. Amsterdam: John Benjamins Publishing.

Johnson, Mark. 1987. The body in the mind: The bodily basis of meaning, imagination, and reason. Chicago: The University of Chicago Press.

Johnson, Mark. 2005. The philosophical significance of image schemas. In Hampe, Beate \& Grady, Joseph E. (eds.), From Perception to Meaning. Image Schemas in Cognitive Linguistics, 15-33. Berlin: Mouton de Gruyter.

LDOCE: Longman Dictionary of Contemporary English. 2001. Harlow: Longman.

Lewis, Diana M. 2006. Discourse markers in English: A discourse-pragmatic view. In Fischer, Kerstin (ed.), Approaches to Discourse Particles, 43-59. Amsterdam: Elsevier.

Lyons, Chistopher. 1999. Definiteness. Cambridge: Cambridge University Press.

Macmillan: Macmillan Dictionary; https://www.macmillandictionary.com (Accessed 2018-04-05).

MWD: Merriam-Webster Dictionary; http://www.merriam-webster.com/dictionary/time (Accessed 2018-04-05).

Nattinger, James R. \& DeCarrico, Jeanette S. 1992. Lexical phrases and language teaching. Oxford: Oxford University Press.

Oxforddictionaries: Oxford Dictionaries: English Dictionary, Thesaurus, \& grammar help; https://en.oxforddictionaries.com (Accessed 2018-04-05).

Potapenko, Serhiy. 2016. Cognitive rhetoric of effect: energy flow as a means of persuasion in inaugurals. Topics in Linguistics 17(2).

Quirk, Randolph \& Greenbaum, Sydney \& Leech, Geoffrey \& Starvik, Jan. 1985. A Comprehensive Grammar of the English Language. London: Longman.

Reid, Wallis. 2004. Monosemy, homonymy and polysemy. In Contini-Morava, Ellen \& Kirsner, Robert S. \& Rodrigez-Bachiller, Betsy (eds.), Cognitive and Communicative Approaches to Linguistic Analysis, 131-150. Amsterdam: John Benjamins Publishing.

Rosch, Eleanor. 1978. Principles of Categorization. In Rosch, Eleanor \& Lloyd, Barbara B. (eds.), Cognition and Categorization, 27-48. Hillsdale: Lawrence Erlbaum.

Schwenter, Scott A. \& Traugott, Elizabeth C. 2000. Invoking scalarity: The development of in fact. Journal of Historical Pragmatics 1(1). 7-25.

Taylor, John R. 1995. Linguistic Categorization. Prototypes in Linguistic Theory. Oxford: Oxford University Press.

Taylor, John R. 2007. Ten Lectures on Applied Cognitive Linguistics. Beijing: Foreign Language Teaching and Research Press. 
Tomasello, Michael. 2000. First steps toward a usage-based theory of language acquisition. Cognitive Linguistics 11(1/2). 61-82.

Tyler, Andrea \& Evans, Vyvyan. 2003. The Semantics of English Prepositions. Spatial Scenes, Embodied Meaning and Cognition. Cambridge: Cambridge University Press.

Wible, David. 2010. Multiword expressions and the digital turn. In Meunier, Fanny \& Granger, Sylviane (eds.), Phraseology in Foreign Language Learning and Teaching, 163-181. Amsterdam: John Benjamins Publishing.

Wray, Alison. 2002. Formulaic Language and the Lexicon. Cambridge: Cambridge University Press.

Zeschel, Arne. 2009. What's (in) a construction? In Evans, Vyvyan (ed.), New Directions in Cognitive Linguistics, 185-200. Bangor: Bangor University Press. 